\title{
13 \\ AccessNova: Broadband networks and multimedia services experiments in Chile $^{\dagger}$
}

Ricardo Baeza-Yates ${ }^{a}$, José Miguel Piquer $^{a}$, Eduardo Vera ${ }^{a}$, Masatoshi Makino $^{b}$, and Yuji Inoue

a Computer Science Department (DCC) \& Science and Technology Information Center (ICT) University of Chile, Santiago, Chile

${ }^{b}$ Telecommunication Network Laboratory Group, NTT Laboratories, Yokosuka \& Musashino, Japan

\begin{abstract}
We describe the technology platform of AccessNova, an advanced communications project to develop high speed networks and to promote the early use of broadband applications in Chile, as the initial step in the implementation of this research and development program. In its first stage (1995-1996), this project has been a joint effort of the University of Chile and the Nippon Telegraph and Telephone Corporation (NTT). In its second stage (1997-1999), AccessNova will be expanded to include other national and international organizations as well.
\end{abstract}

Keywords

Broadband Networks, Multimedia Services, Internet

\section{INTRODUCTION}

Chile is located on the southwest coast of South America, spanning over $4300 \mathrm{kms}$, with an area of 750 thousand square kilometers and 14 million people. Although Chile's economy is mainly based on raw materials (minerals, lumber, fish, fruit), value-added exports are

$\uparrow$ This work was partially supported by the Andes Foundation. 
increasing. In particular, the software exports in 1995 were estimated in US\$ 50 million, showing an annual growth greater than $40 \%$ in the last five years.

Chile is a good example of a country with a small but very open internal market and a reasonably good technological level, in contrast to other Latin American countries that have larger but less competitive internal markets. According to IDC (International Data Coorporation), in 1993 Chile spent US $\$ 42$ per capita on information technology (IT), second in Latin America after Mexico (US\$ 44 before the peso devaluation). Currently, about $1.1 \%$ of the country's GDP is spent on IT. As is characteristic of Latin American countries, most of the market is concentrated in the capital city, Santiago, which holds $40 \%$ of the population of Chile. A broader IT view of Chile in particular related to software exports can be found in [Baeza-Yates et al., 1995].

\section{OVERVIEW OF INFORMATION TECHNOLOGY IN CHILE}

Due to the openness of the market and the full privatization of the telecommunication sector 8 years ago, the network infrastructure has seen a radical improvement. In fact, Chile is now being used by several multinational companies as a testbed for new technology and marketing strategies in a competitive arena. According to ITU (International Telecommunications Union), Chile is ranked 29 in multimedia access technology, second only to Argentina in Latin America. In 1994, Chile had 110 telephones, 230 TVs and 31 PCs per one thousand inhabitants.

In telephony, the number of lines tripled to 1.8 million in 6 years since 1989 , and all the public switching is now digital. In 1994 a multicarrier long-distance system started, and 8 companies (half of them foreign) are offering this service. Currently, three local companies share $80 \%$ of the market, and prices have lowered significantly (for instance, in August 1995, a one-minute call to the USA was less than 50 cents).

Cellular telephony is available almost everywhere in Chile through four companies, one of them foreign (BellSouth). The law allows two companies per region. Basic service costs range from US $\$ 20$ to 50 per month including a certain number of free calls and a free cellular phone.

Fiber optic lines have been installed by three different companies from La Serena in the north to Valdivia in the south which are separated by a distance of $1300 \mathrm{~km}$. There is also a fiber optic connection to Buenos Aires, Argentina, which links to coastal and transatlantic cables. In 1996 fiber optic lines will be extended to Arica in the north and Puerto Montt in the south, spanning over $3000 \mathrm{~km}$. Sometime in 1997, Chile is expected to have access to the Pacific coastal cables that are currently being installed by various consortia, which will connect North and South America.

Due to certain developments (discussed below), several companies provide data lines, starting from $64 \mathrm{kbps}$ to several Mbps. Internet in Chile became available in 1992 via two different academic consortia (although electronic mail via UUCP started in 1986). In 1995 the number of providers jumped to six, with several resellers covering all major cities. The approximate number of hosts was 12,000 in May 1996. It is estimated that at least 50 thousand people had access to the Internet in 1995. The overall international bandwidth of the Internet connections has progressed from $128 \mathrm{Kbps}$ in 1992 to more 
than $1 \mathrm{Mbps}$ in 1995. A discussion about the start of Internet in Chile can be found in [Baeza-Yates et al., 1993].

In 1995 there were 76 CATV operators in the main cities, owned by 15 different companies, and reaching about 390 thousand homes ( $15 \%$ of the country's homes, $80 \%$ located in Santiago) at an approximate monthly cost of US\$20. In total, they offer more than 150 channels, 70 of them locally broadcasted. Foreign signals are mainly from Argentina (where cable reaches $50 \%$ of all households) and the United States.

Narrowband ISDN services started in 1994 (only in Santiago) and the first ATM network was installed in 1994 at the University of Chile. In 1995, several other private ATM networks were installed (at Catholic University, the National Congress, etc.). In 1996, two main telecom carriers (CTC and ENTEL) built public ATM networks, mainly offering LAN to LAN emulations to corporate clients.

Another remarkable success story is the boom of WWW servers containing multimedia material, due to the early adoption of that Internet tool. In 1993, Chile introduced the first WWW server in Latin America, with the total number of servers surpassing 100 in 1995. Currently many universities as well as some public and private institutions have WWW servers. In September of 1995 there were more than 40 physical and 80 logical servers (including 35 academic, 30 commercial, and 10 government). Their main use is for online information and marketing. Visitors can access many of them through an interactive map of Chile at http://sunsite.dcc.uchile.cl/chile/chile.html. Nowadays there are several magazines and newspapers available via WWW, as well as radio and TV news summaries. There is also an electronic magazine sponsored by the Chilean Computer Science Society (SCCC). About 30 electronic bulletin board systems exist, half of them are on Fidonet and the rest are connected to Internet.

An interesting example of Internet use is the software La Plaza, which has had an international impact on K-12 education, being awarded in 1995 a prize by Apple for premier educational applications. This software was developed as part of the Ministry of Education's Enlaces Project, whose main goal is to deploy a network of schools in a rural area of southern Chile, and soon throughout the rest country. La Plaza is a metaphor for a public city square, an important meeting place in Spanish American culture. In this environment a child has easy access to electronic mail, news, educational material, and so forth, through a very friendly and simple user interface. As a result, more than 100 schools can share ideas and experiences, improving the technological level of education in Chile. During 1995 this project expanded to secondary school along all the country.

The financial sector has been very aggressive in the adoption of new technologies. Banks, in particular, have widely introduced automatic teller machines and electronic information booths. The most recent development is the virtual or interactive bank, which connects the customer with a bank attendant using real-time video conferencing (presently, at least two banks offer this service, which is available 24 hours). On the other hand, EDI was introduced in 1994, but has not been used as much as expected. Banks have also begun during 1995 providing software and services such as on-line access to checking accounts. Eight banks already have WWW servers, three of them providing remote electronic banking services. There are no public estimates of the number of customers using this system yet.

In 1994, the first experimental telemedicine application appeared, intended to provide expertise to sectors with fewer resources. Using an ATM network, the hospital of the 
Catholic University at Santiago is performing telediagnosis[Mena B et al., 1996]. This ATM system is fully operational since the end of 1995. The Health Ministry is now planning a nationwide narrowband system.

\section{ACCESSNOVA PROJECT (1995-1999)}

\subsection{ATM/B-ISDN Experiments in Chile}

Throughout its history, the University of Chile (UChile) has contributed to Chile's development in diverse ways. From operating the country's first mainframe in the early 1960's to inaugurating Latin America's first ATM multicampus MAN in 1994, UChile has played a key role in the advancement of local scientific and technological know-how, especially in the area of data networks and distributed computer systems.

Given the successful transformation of its telecommunications industry, Chile is in a unique situation to become a real player in the development of global communications, consolidating its leadership position in Latin America. Furthermore, the country will need, not only to be on the telecommunications frontier, but also to become an innovator in "content generation," that is digitizing high quality information of worldwide interest. Fulfilling this historic opportunity is the main purpose of the new "Science and Technology Information Center" (ICT) at UChile, one of the most ambitious projects started in this country. ICT is strongly supported by the academic activities of the Dept. of Computer Science (DCC) and the Dept. of Electrical Engineering (DIE) at UChile's School of Engineering and Sciences.

In this context, UChile recently concluded a cooperative research agreement with the Nippon Telegraph and Telephone Corporation (NTT). Under the terms of the AccessNova Project, started in November 1994, NTT will support UChile in formulating a strategy for the introduction and development of B-ISDN (Broadband Integrated Services Digital Network) in Chile, by proposing a plan to jointly carry out testing and experiments on high-speed networks and broadband applications. The project, which will be implemented through ICT, is aimed at completing a next-generation telecommunications network and services in Chile during the period 1995-1999 by installing super-high-speed, large-capacity experimental transmission lines $(2.4 \mathrm{Gbps})$ in its ATM backbone network. This experimental network begun operation by early 1996 .

Nowadays, a Science and Technology Information Center needs to use the latest multimedia technologies available, including high-resolution images, with text, audio and video. This type of application requires wider bandwidths than present day technologies, such as ethernet are able to deliver. For this reason, we believe that ICT should play a pioneering role in incorporating into its information systems broadband networks, based on fully optical ATM platforms. On the other hand, the software applications which can make good use of such robust infrastructure are not yet fully developed. Access to world-class research and development centers is absolutely necessary for the beta testing stage. What we aim at initially is building an experimental ATM network at ICT that will allow us to bring full ATM capabilities to the workstation level.

The AccessNova Project is based in the present existence of the CTC (Chile Telecom- 
munications Corporation) ATM-MAN backbone, which is a public service network with two ALCATEL 1000AX ATM Switching Systems. At present, the network has only one single customer (UChile) but it is a shared vision of CTC and UChile that other public or private organizations and companies will be linked to it in the near future. The AccessNova Project will contribute significantly to the realization of this vision by creating an experimental ATM platform that will allow us to test network performance and new applications, first within UChile and, later, on a continuously expanded basis.

Within this framework, the AccessNova Project is a highly interdisciplinary and interinstitutional effort. Thus, it is being implemented by ICT in strong coordination with DIC, UChile's Division of Informatics and Communications, responsible with CTC of building and running the multicampus ATM-MAN in Santiago. Besides CTC, AccessNova is also planning to collaborate with other local and international technology companies such as Apple Chile, TANDEM CHILE, SUN Microsystems and NEC Corporation.

Advanced computer and communication equipment is now in place, including a number of SUN workstations (SUN Sparc 20 and Ultra) as well as one high capacity server (SUN Sparc 1000) with 4 parallel processors, $128 \mathrm{MB}$ RAM and 21GB hard disk with several ATM cards to test the effects of broadband desktop capability. Two CISCO 4000 Routers, two NEC ATOMIS-5 ATM switches and one FORE ASX-200 ATM switch, guarantee high level connectivity at ICT. These ATM switches are to be interconnected to the ALCATEL $1000 \mathrm{AX}$ public nodes as well as to other ATM nodes from the future ATM-LAN systems that will undoubtely surface.

Additionally, another high capacity server SUN Sparc 1000 with 2 parallel processors, $128 \mathrm{MB}$ RAM and 44 GB hard disk is located at the Computer Sciences Department (DCC). This computer is one in 27 similar servers which SUN has given worldwide to leading regional universities to promote the use of Internet. The selection of UChile as the first South American SUNSITE is a reflection of UChile's pioneering role in the successful development of Internet in Chile. At present, an expanded proposal to create a SUN Lab for multimedia academic teleconferencing at ICT-UChile is in its final approval stages.

AccessNova is the first B-ISDN project that NTT is involved out of Japan. The high speed multimedia experiments that Chilean and Japanese researchers will jointly perform (first locally, then trans-continentally), will be an authentic proof of the full potential of global broadband networks that will allow collaborative work in the distance (telework) on a planetary scale. At present, a group of 18 researchers (9 in each country) is actively collaborating to establish the AccessNova Tokyo-Santiago Virtual Laboratory for the implementation of the project. Other applications include remote education, video on demand and high-definition TV.

\subsection{The Platform Master Plan}

The AccessNova Master Plan, establishes the framework for the development of the AccessNova experimental ATM network, in cooperation with CTC. The high-speed network described, has been designed as a key element of AccessNova's strategy to introduce broadband applications in Chile. By jointly experimenting and testing bandwidth demanding applications in the AccessNova network, the UChile and NTT teams hope to encourage the development and promote the use of new broadband services (B-ISDN) in Chile, as well as in other South American countries. 
The broadband experiments will focus on three main application services, supported by the AccessNova ATM network in order of increasing complexity, as follows:

- Digital TV Transmission: this application will allow ICT to internally broadcast information and lectures by transmitting digital video signals through an ATM network (high resolution) as well as through the conventional networks (low resolution).

- Video Conference: this application will allow high resolution multimedia assisted video conferences over ATM network.

- Remote Education: this applications will allow a professor to interact with students remotely over an ATM network. All the teaching material will be available in digital form using computer workstation servers. Other functionalities (like remote control of cameras, teacher-student eye contact) will be gradually introduced.

In order to cope with the increasing complexity better, all these service experiments will be first implemented over local networks, extending their coverage, as follows:

- Local Area Network (DCC)

- Campus Network (ICT-DCC)

- University Network (ICT-DIC)

- Metropolitan Network (ICT-UCatholic, CINCATEL)

- National Network (ICT-USantaMaria, ProChile)

- International Network (ICT-NTT)

The last phase should be operating in 1998 .

\subsection{Preliminary Experiments}

We have built an ATM experimental network, using two ATM nodes: a FORE ASX-200 and a NEC Atomis-5. Using these nodes, we connected some SUN Ultra 1 and Sparc 20 workstations using Fore-200 cards with $155 \mathrm{Mbps}$ multimode links. Figure 1 shows our current setup.

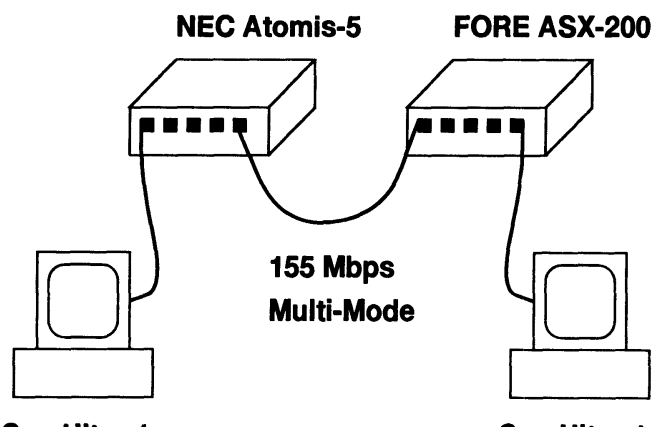

Sun Ultra-1

Sun Ultra-1

Figure 1 ATM Laboratory 
Our main research interest is the enhanced broadband Internet, so we are always using IP as our network protocol. This introduces the need of a well-powered CPU: only the Ultra Sparcs were able to deliver a significant speedup on ATM. All the tests were done on a local ethernet and on ATM, to try to compare the results. In a middle-end workstation the TCP/IP processing overhead is the main bottleneck, giving almost the same results on ATM or ethernet. A single point-to-point file transfer (using FTP) between two SUN Ultras through our ATM switches, gave a 50 Mbps performance.

The first series of experiments concern audio and video over IP and ATM. For these preliminary tests, we use the MBONE[Derring S., 1991] tools, in particular vat (visual audio tool) and nv (network video). For the first test, we sent a conference on ATM and on ethernet (using multicast) at the same time. The video grabber was on an Ultra 1, and the ATM receiver also. With this setup, we were able to get $4 \mathrm{Mbps}$ for the video alone, displaying $30 \mathrm{frames} / \mathrm{s}$ in the receiver. In the ethernet version, we used $128 \mathrm{Kbps}$, display in 7 frames/s. If the receiver in ATM was a Sun Sparc 20, we kept losing frames (more than 50\%), not being able to catchup with the sender speed. The performance in this case is much worse than in a normal ethernet.

As nv uses a good compression algorithm, a static picture displayed almost the same quality in both networks. However, in case of motion the differences were quite impressive.

Our second test was to send the video on ATM first, and then to use a reflector to multicast it (at a lower bandwidth) in the campus network. This test is under construction now, and will be operational in June 1996. The main objective is to provide IP multicasting on ATM.

In general, it seems obvious that the software implementation of TCP/IP needs some work to be able to use the available bandwidth, without consuming too much CPU. However, we were able to show a movie in a remote X-windows display through ATM, at exactly the same performance as on a local display. It seems that the available CPU power on Sun Ultras is enough to cope with the overhead.

\section{FUTURE DEVELOPMENTS}

The successful implementation of the project's Master Plan will guarantee that the goals set in November 1994 for AccessNova during the 1995-1996 period are thouroughly fulfilled. Thus, laying the foundations for the future expansion of the project, to include local telecommunications providers (such as CTC) and other national and international technology companies (TANDEM CHILE and SUN Microsystems, among them) within the 1997-1999 timeframe.

To promote global advanced communications, we are planning to use this high-speed network infrastructure, as a testbed for "worldwide broadband demos" in four important international events to take place in Chile, as follows:

1. The Centennial of Chile-Japan Commercial Relations: with an important joint anniversary event to be held simultaneously in Santiago and Tokyo (25 Sep 1997).

2. TINA'97: the research consortium international conference that will take place in Santiago (Oct 1997). 
3. PECC'97: the next Pacific Economic Cooperation Council Meeting to be held in Santiago (Nov 1997).

4. PBEC'98: a following meeting of the Pacific Basin Economic Council to be held in Santiago (1998)

Our strategic aim is to use these pilot demos to trigger the use of advanced remote interactive broadband applications not only between Chile and Japan but eventually between other South American and Asian countries as well. We strongly believe that to long term promote such broadband evolution within the Pacific Basin region, the building of local expertise is a task that needs to start right away with small scale experimental projects such as AccessNova.

\section{REFERENCES}

[Baeza-Yates et al., 1995] Baeza-Yates, R., Fuller, D., Pino, J., and Goodman, S. (1995). Computing in Chile: The jaguar of the Pacific rim? Communications of the ACM, 38:23-28.

[Baeza-Yates et al., 1993] Baeza-Yates, R., Piquer, J., and Poblete, P. (1993). The Chilean internet connection or I never promised you a rose garden. In INET'93, San Francisco. [Derring S., 1991] Derring S. (1991), Multicast routing in a datagram internetwork (1991), PhD Thesis, Stanford University, California.

[Mena B et al., 1996] Mena B., Badía J., Neira M. and Ríos A. (1996). Medical architects design networks to suit environs. In Telemedicine and Telehealth Networks, 25-29. 